\title{
Ultra-thin Cu2ZnSnS4 solar cell by pulsed laser deposition
}

Cazzaniga, Andrea Carlo; Crovetto, Andrea; Yan, Chang; Sun, Kaiwen; Hao, Xiaojing; Estelrich, Joan Ramis; Canulescu, Stela; Stamate, Eugen; Pryds, Nini; Hansen, Ole

Total number of authors:

11

Published in:

Solar Energy Materials \& Solar Cells

Link to article, DOI:

10.1016/j.solmat.2017.03.002

Publication date:

2017

Document Version

Early version, also known as pre-print

Link back to DTU Orbit

Citation $(A P A)$ :

Cazzaniga, A. C., Crovetto, A., Yan, C., Sun, K., Hao, X., Estelrich, J. R., Canulescu, S., Stamate, E., Pryds, N., Hansen, O., \& Schou, J. (2017). Ultra-thin Cu2ZnSnS4 solar cell by pulsed laser deposition. Solar Energy Materials \& Solar Cells, 166, 91-99. https://doi.org/10.1016/j.solmat.2017.03.002

\section{General rights}

Copyright and moral rights for the publications made accessible in the public portal are retained by the authors and/or other copyright owners and it is a condition of accessing publications that users recognise and abide by the legal requirements associated with these rights.

- Users may download and print one copy of any publication from the public portal for the purpose of private study or research.

- You may not further distribute the material or use it for any profit-making activity or commercial gain

- You may freely distribute the URL identifying the publication in the public portal 


\title{
Ultra-thin $\mathrm{Cu}_{2} \mathrm{ZnSnS}_{4}$ solar cell by pulsed laser deposition
}

\author{
Andrea Cazzaniga ${ }^{\mathrm{a}, 1}$, Andrea Crovetto $^{\mathrm{b}, \mathrm{c}, 1, *}$, Chang Yan ${ }^{\mathrm{c}}$, Kaiwen Sun ${ }^{\mathrm{c}}$, Xiaojing Hao ${ }^{\mathrm{c}}$, Joan Ramis Estelrich ${ }^{\mathrm{a}}$, Stela Canulescu ${ }^{\mathrm{a}}$, \\ Eugen Stamate ${ }^{\mathrm{d}}$, Nini Pryds ${ }^{\mathrm{d}}$, Ole Hansen ${ }^{\mathrm{b}, \mathrm{e}}, \mathrm{J} \varnothing \mathrm{rgen} \mathrm{Schou}{ }^{\mathrm{a}}$ \\ ${ }^{a}$ DTU Fotonik, Technical University of Denmark, DK-4000 Roskilde, Denmark \\ ${ }^{b}$ DTU Nanotech, Technical University of Denmark, DK-2800 Kgs. Lyngby, Denmark \\ ${ }^{c}$ School of Photovoltaic and Renewable Energy Engineering, University of New South Wales, NSW 2052, Sydney Australia \\ ${ }^{d}$ DTU Energy, Technical University of Denmark, DK-4000 Roskilde, Denmark \\ ${ }^{e}$ V-SUSTAIN, Villum Center for the Science of Sustainable Fuels and Chemicals, Technical University of Denmark, DK-2800 Kgs. Lyngby, Denmark
}

\begin{abstract}
We report on the fabrication of a $5.2 \%$ efficiency $\mathrm{Cu}_{2} \mathrm{ZnSnS}_{4}$ (CZTS) solar cell made by pulsed laser deposition (PLD) featuring an ultra-thin absorber layer (less than $450 \mathrm{~nm}$ ). Solutions to the issues of reproducibility and micro-particulate ejection often encountered with PLD are proposed. At the optimal laser fluence, amorphous CZTS precursors with optimal stoichiometry for solar cells are deposited from a single target. Such precursors do not result in detectable segregation of secondary phases after the subsequent annealing step. In the analysis of the solar cell device, we focus on the effects of the finite thickness of the absorber layer. Depletion region width, carrier diffusion length, and optical losses due to incomplete light absorption and back contact reflection are quantified. We conclude that material- and junction quality is comparable to that of thicker state-of-the-art CZTS devices, even though the efficiency is lower due to optical losses.
\end{abstract}

Keywords:

CZTS, $\mathrm{Cu}_{2} \mathrm{ZnSnS}_{4}$, kesterite, pulsed laser deposition, ultra-thin

\section{Introduction}

Considerable research effort is presently devoted to alternative earth-abundant and non-toxic materials for photovoltaic applications. In this context, the p-type chalcogenide semiconductor $\mathrm{Cu}_{2} \mathrm{ZnSnS}_{4}$ (CZTS) has become very popular due optimal direct bandgap at $1.5 \mathrm{eV}$, high absorption coefficient $>10^{4}$ $\mathrm{cm}^{-1}$ and its rapid technological development in the last decade $[1,2]$. Still, the current record efficiency of $12.6 \%$ for CZTSSe [3] and of $9.1 \%$ for pure-sulfide CZTS [4] is far below the $21.7 \%$ efficiency demonstrated by the very similar CIGS technology [5], from which they borrow most of the device architecture. Regarding the pure sulfide CZTS, different vacuum deposition techniques have been successfully employed, such as cosputtering $[4,6-8]$ and co-evaporation [9-12]. The most successful strategies to date consist of a two stage process, where precursors are prepared at a substrate temperature below $300^{\circ} \mathrm{C}$, followed by a high temperature annealing $\left(>500^{\circ} \mathrm{C}\right)$ done separately at much higher pressures. Among vacuum techniques, pulsed laser deposition (PLD) was firstly studied in 2007-08 by Moriya et al. [13, 14], who demonstrated a power conversion efficiency up to $1.74 \%$ with a two stage approach consisting of room temperature deposition of the precursors followed by high temperature annealing in a mixture of $\mathrm{N}_{2}$ and $\mathrm{H}_{2} \mathrm{~S}$. With a similar approach, but using a quaternary oxide target, a power

\footnotetext{
*Corresponding author, email: ancro@ nanotech.dtu.dk, Ørsteds Plads, building 345 East, DK-2800 Kgs. Lyngby, Denmark, Tel.: +45 4525845

${ }^{1}$ These authors contributed equally to this work.
}

conversion efficiency of $4.94 \%$ was claimed very recently by Jin et al. [15]

Pulsed laser deposition is a non-equilibrium technique that enables the fabrication of high quality thin films with complex stoichiometry, particularly oxides, nitrides, and amorphous materials [16-18]. Briefly, a pulsed UV laser beam is focused onto a solid target and laser ablation occurs, which result in highly non-thermal removal of the target material. The ablated material, which is an expanding plasma cloud, is finally collected onto a substrate placed a few $\mathrm{cm}$ away. The fact that the energy source is outside of the vacuum chamber and decoupled from the deposition process enables one to investigate many experimental parameters (background gas pressure, substrate temperature, ablation energy density) over a wider physical range than with other vacuum techniques. Since the laser heating and subsequent plasma formation are confined in a very small region of the target, there is no risk of contaminating the growing film with materials coming from components of the chamber other than the target itself. The kinetic energy of the atoms and ions in the deposition flux is related to the laser fluence and is usually of few eV. Particularly relevant to this work, PLD has proven to be a very successful technique in the growth of high quality films of amorphous structure $[18,19]$. This ability comes from a few combined features: the possibility to keep the substrate at room temperature with relative ease, the sticking coefficient close to unity for all incoming species, and both compactness and flatness of deposited films due to the highly energetic instantaneous material flux [16, 19]. However, reproducibility is often reported to be an issue, mostly because it is difficult 


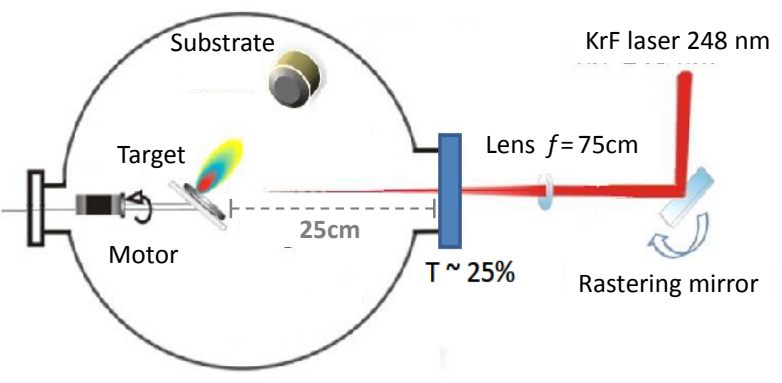

Figure 1: Sketch of the PLD setup. The laser pulses are focused on the target at 45 degrees from normal incidence with a focal lens. The fluence on the target was $0.6 \mathrm{~J} / \mathrm{cm}^{2}$ with a spot size of $4 \mathrm{~mm}^{2}$.

to keep the laser ablation parameters within the desired range throughout the whole deposition process, especially in the case of strong coating on the laser viewport [20]. Droplet production and target deterioration are also issues in PLD [16]. Such problems have already been recognized as hurdles to production of high-efficiency solar cells by PLD [21].

However, in this work we demonstrate that it is possible to circumvent most of the above problems and obtain a CZTS solar cell efficiency above 5\%. Interestingly, this result is achieved with an "ultra-thin" absorber layer, with thickness below $450 \mathrm{~nm}$.

\section{Experimental Details}

A $10 \times 10 \mathrm{~cm}^{2}$ soda lime glass (SLG) substrate was sequentially cleaned in acetone and isopropanol in an ultrasonic bath (5 min each), rinsed in deionized water, and dried with nitrogen. A Mo bilayer was deposited by DC magnetron sputtering at 10 $\mathrm{W} / \mathrm{cm}^{2}$ power density. The first layer was $200 \mathrm{~nm}$ thick and deposited at a working pressure of $1.3 \times 10^{-2}$ mbar for good adhesion to the substrate. The second layer was $300 \mathrm{~nm}$ thick and deposited at a working pressure of $3.9 \times 10^{-3}$ mbar to achieve a lower sheet resistance. The sheet resistance of the Mo bilayer was $0.7 \Omega / \mathrm{sq} \pm 50 \%$ depending on position on the SLG substrate. The Mo-coated glass was cut into $1.5 \times 3 \mathrm{~cm}^{2}$ substrates, which were cleaned in the same way as above prior to pulsed laser deposition of CZTS precursors. Precursors were deposited with our PLD equipment, depicted schematically in Fig. 1, under high vacuum with $p<5 \times 10^{-6}$ mbar. The KrF excimer laser beam ( $248 \mathrm{~nm}$ wavelength, $20 \mathrm{~ns}$ pulse-width, $15 \mathrm{~Hz}$ pulse repetition rate) was focused onto a sintered target with overall CZTS stoichiometry $(2.5 \mathrm{~cm}$ diameter, $2 \mathrm{CuS}: \mathrm{ZnS}: \mathrm{SnS}$, Testbourne Ltd) at a laser fluence of $0.6 \mathrm{~J} / \mathrm{cm}^{2}$ and a spot size of $4 \mathrm{~mm}^{2}$.

The laser energy on the target was measured inside the chamber to avoid errors due to strong coating of the viewport with ablated material. The depositions were done after the laser beamviewport system had reached equilibrium, as shown in Fig. 2.

Rastering of the laser and rotation of the target were used to maximize film uniformity and target utilization. The targetsubstrate distance was set to $4 \mathrm{~cm}$ and the substrate was kept at room temperature. Morphology of the precursors, and of

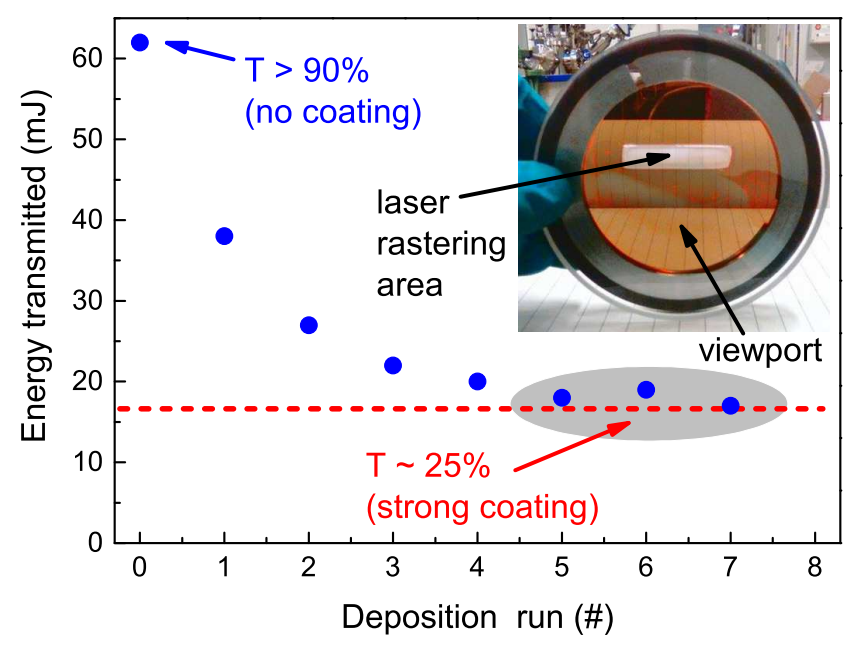

Figure 2: Laser energy transmitted through the viewport as a function of cumulative number of CZTS deposition runs. In the inset: photograph of the viewport after more than five deposition runs, when the transmission coefficient $T$ has reached an equilibrium value of about $25 \%$. The rectangular-shaped region of the viewport through which the laser is rastered is indicated by an arrow. The transmitted energy is measured inside the chamber within that region. One deposition run corresponds to a $20 \mathrm{~min}$ deposition at $10 \mathrm{~Hz}$ pulse repetition rate.

the finished solar cell devices, was examined with a scanning electron microscope (SEM) equipped with a field emission gun (Supra 60VP, Zeiss). The chemical composition of the precursors was measured in the same instrument by energy dispersive X-ray spectroscopy (EDX) using a silicon drift detector $\left(\mathrm{X}-\mathrm{Max}^{N} 50\right.$, Oxford Instruments) and a beam voltage of $15 \mathrm{kV}$. The CZTS precursors were vacuum packed and taken to the University of New South Wales for the annealing treatment and the buffer/window layer deposition. Annealing was conducted at $560^{\circ} \mathrm{C}$ in the presence of $\mathrm{S}$ and $\mathrm{SnS}$ powder in a rapid thermal processor (AS-One 100). The CdS buffer layer $(60 \mathrm{~nm})$ was deposited by a standard chemical bath deposition process [22], followed by RF magnetron sputtering of a window layer consisting of $50 \mathrm{~nm}$ intrinsic $\mathrm{ZnO}(\mathrm{i}-\mathrm{ZnO})$ and $200 \mathrm{~nm}$ indium tin oxide (ITO) having a sheet resistance around $30 \Omega / \mathrm{sq}$. A $1.5 \mathrm{~mm}^{2}$ dot-shaped silver paste contact was applied on the ITO layer, followed by evaporation of $100 \mathrm{~nm} \mathrm{MgF} 2$ as an antireflection coating. Solar cell devices of $0.2 \mathrm{~cm}^{2}$ were defined by mechanical scribing.

Illuminated current-voltage $(\mathrm{J}-\mathrm{V})$ measurements were performed after 5 min light soaking under standard AM 1.5 solar spectrum $\left(100 \mathrm{~mW} / \mathrm{cm}^{2}\right)$ using a solar simulator from PV Measurement calibrated with a standard Si reference and a Keithley 2400 source meter. Due to the coarse nature of the top contact, in this work we present the active area efficiency of the solar cell instead of the total area efficiency. Dark J-V and capacitancevoltage $(\mathrm{C}-\mathrm{V})$ curves were measured with an Agilent B1500A semiconductor device analyzer. C-V scans were performed between $-4 \mathrm{~V}$ (reverse bias) and $+2 \mathrm{~V}$ at a frequency of $100 \mathrm{kHz}$ and an AC voltage of $50 \mathrm{mV}$.

External quantum efficiency (EQE) curves were measured at 


\begin{tabular}{|c|c|c|c|c|c|}
\hline $\begin{array}{l}\text { Solid } \\
\text { Phase }\end{array}$ & $\begin{array}{l}\text { Specific heat } \\
C_{p} \\
\mathrm{~J} /\left(\mathrm{K}^{*} \mathrm{~mol}\right)\end{array}$ & $\begin{array}{l}\text { Melting } \\
\text { point } \\
{ }^{\circ} \mathrm{C}\end{array}$ & $\begin{array}{l}\text { Heat of } \\
\text { Fusion } \\
\mathrm{kJ} / \mathrm{mol}\end{array}$ & $\begin{array}{l}\text { Heat of } \\
\text { vaporization } \\
\mathrm{kJ} / \mathrm{mol}\end{array}$ & $\begin{array}{l}\text { Vapor } \\
\text { products }\end{array}$ \\
\hline $\mathrm{CuS}$ & 47.8 & $220^{*}$ & s.s.r 1 & & $\mathrm{~S}_{2(g)}$ \\
\hline $\mathrm{Cu}_{1.75} \mathrm{~S}$ & 76.3 & $507 *$ & s.s.r 2 & & $\mathrm{~S}_{2(g)}$ \\
\hline $\mathrm{Cu}_{2} \mathrm{~S}$ & 76.3 & 1129 & 9.62 & N.A. & N.A. \\
\hline $\mathrm{SnS}$ & 49.3 & 881 & 31.6 & 220 (subl.) & $\mathrm{SnS}_{(g)}$ \\
\hline $\mathrm{ZnS}$ & 46.0 & 1827 & 30.0 & 206 (subl.) & $\mathrm{ZnS}_{(g)}, \mathrm{Zn}, \mathrm{S}_{2(g)}$ \\
\hline
\end{tabular}

Table 1: Physical properties of the most relevant solid state phases in the sintered target. Other binary and ternary chalcogenide phases are not excluded, but no metallic phases were found. Subscripts (s)/(g) indicate solid/gas. Melting temperatures marked with * relate to the solid state reaction (s.s.r.) mentioned in the text. Heat of vaporization is only given for compounds that can be fully evaporated, either congruently or via dissociation product. The "N.A." (not available) label means that no data could be found in the literature. Data from [23-25].

0V and -1V dc bias in the range 300 to $1000 \mathrm{~nm}$ with a QEX10 spectral response system (PV measurements, Inc.) calibrated by the National Institute of Standards and Technology (NIST)certified reference $\mathrm{Si}$ and $\mathrm{Ge}$ photodiodes. The band gap of CZTS was extracted from the inflection point of the EQE curve, i.e., as the photon energy at which $-\mathrm{d}(\mathrm{EQE}) / \mathrm{d} \lambda$ has a maximum [26].

Steady-state photoluminescence (PL) spectra were measured on completed solar cells with an Accent RPM2000 system at an excitation wavelength of $532 \mathrm{~nm}$ and power density $100 \mathrm{~W} / \mathrm{cm}^{2}$. On the other hand, Raman spectroscopy, X-ray diffraction (XRD), and time-resolved photoluminescence (TRPL) were performed on a bare CZTS absorber layer deposited on Mo-coated SLG. It was fabricated similarly to the absorber used for the solar cell. Raman spectra with multiple excitation wavelengths $(455,532$, and $780 \mathrm{~nm})$ were measured with a DXR Raman microscope (Thermo Scientific) in backscattering configuration, with a laser power of $1.6 \mathrm{~mW}$ and a spot size of approximately $2 \times 2 \mu \mathrm{m}^{2}$. X-ray diffraction (XRD) patterns were recorded with a Bruker D8 diffractometer in BraggBrentano configuration. TR-PL was measured using the timecorrelated single photon counting (TCSPC) technique (Microtime200, Picoquant). The excitation wavelength was $470 \mathrm{~nm}$ and the power density was $1 \mathrm{~W} / \mathrm{cm}^{2}$, with a pulse frequency of $10 \mathrm{MHz}$ and a 780-820 $\mathrm{nm}$ detection range.

\section{Results and discussion}

\subsection{CZTS precursors preparation}

In this study we aimed for amorphous precursors by keeping the substrate at room temperature during deposition. Under such conditions, stoichiometry and morphology of the films are primarily related to the laser beam-target interaction, which is very complex here due to the multi-phase structure of the target, as shown in Fig. 3. Since a single crystal target is not commercially available, the target used in this work is made from sintered powders (2CuS:ZnS:SnS). The different phases extend over many hundreds of $\mu \mathrm{m}$ and have very different physical properties in terms of energy absorption, decomposition mechanisms and volatility in vacuum, as summarized in Table 1.

As a matter of fact, the $\mathrm{Cu} /(\mathrm{Zn}+\mathrm{Sn})$ and $\mathrm{Zn} / \mathrm{Sn}$ ratios in the precursors are of paramount importance to achieve good quality devices [27]. Therefore, we start our discussion with the

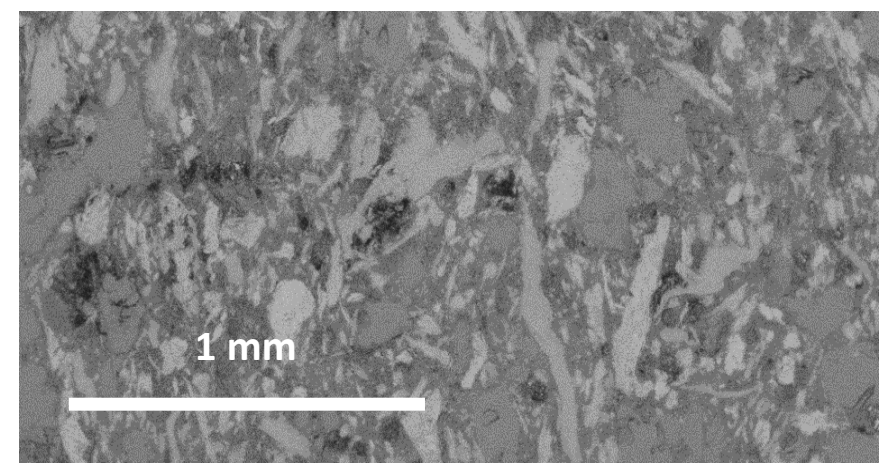

Figure 3: SEM image of the CZTS (2CuS:ZnS:SnS) sintered target. The different phases are clearly visible and extend over a typical length scale of a few hundred $\mu \mathrm{m}$. The melting point and the vapor pressure of the main phases are summarized in Table 1. The laser beam, continuously rastered across the target, has a spot size of $4 \mathrm{~mm}^{2}$.

stoichiometry of films deposited in the laser fluence range from 0.2 to $1.2 \mathrm{~J} / \mathrm{cm}^{2}$, as shown in Fig. 4. Noteworthy, the copper content in the as-deposited films is found to be strongly related to the laser fluence, while the $\mathrm{Zn} / \mathrm{Sn}$ ratio is always close to the target stoichiometry. First, a threshold fluence for copper transfer is clearly visible at $0.2 \mathrm{~J} / \mathrm{cm}^{2}$. In the "low fluence" range from 0.2 to $0.8 \mathrm{~J} / \mathrm{cm}^{2}$, the $\mathrm{Cu}$ content steadily increases from $0 \%$ to its stoichiometric value, same as the target. In the "high fluence" range above $0.6 \mathrm{~J} / \mathrm{cm}^{2}$ the films become Cu-rich and the $\mathrm{Cu}$ content saturates above its stoichiometric value. The sulfur content is not shown here, but a behaviour opposite to copper is seen, i.e., it steadily decreases from low to high laser fluences. Changes in films composition are also followed by changes in films morphology. SEM images of three films deposited with different laser fluences are shown in Fig. 5. The as-deposited films are amorphous and, in particular, (b) and (c) are studded with micron-sized droplets which are primarily a mixture of copper and sulfur [28]. From Figures 4 and 5 it is clear that, by increasing the laser fluence, both the copper content in the films and the amount of $\mathrm{Cu}-\mathrm{S}$ droplets are increasing.

While laser ablation is not an evaporation process at thermodynamic equilibrium, still, a qualitative understanding of the fluence dependence of composition and morphology of the deposited films can be proposed on the account of thermodynam- 


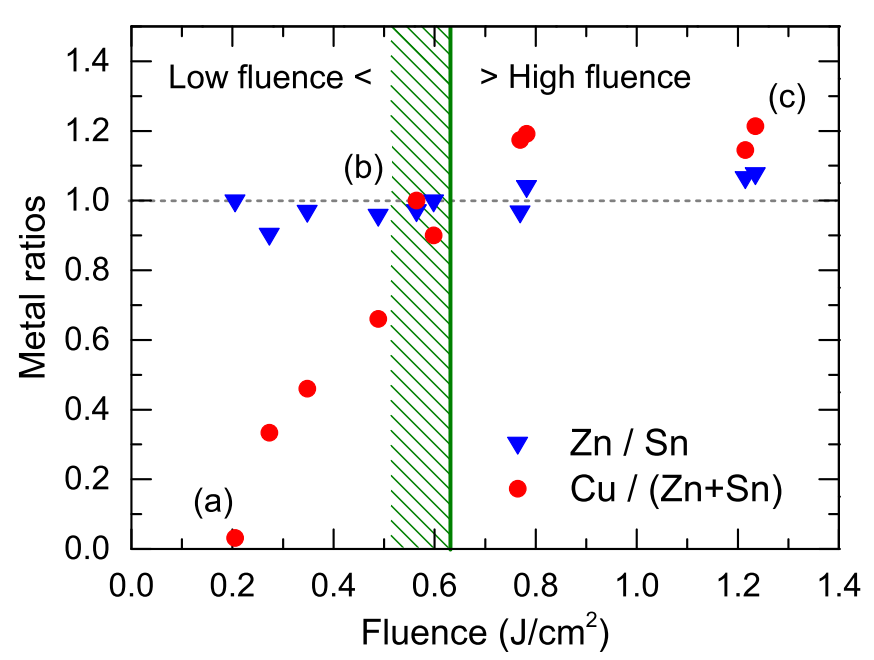

Figure 4: The CZTS metal ratios as a function of laser fluence as measured by EDX in the films deposited at room temperature. The (a)-(c) labels indicate the corresponding films shown in Fig. 5(a)-(c). The fluence range used for preparing the solar cells precursors is indicated by the green shaded area. The fluence value (approximately $0.6 \mathrm{~J} / \mathrm{cm}^{2}$ ) that results in stoichiometric transfer is marked with a green line. Below and above this reference fluence, we speak of "low fluence" and "high fluence" in the main text.
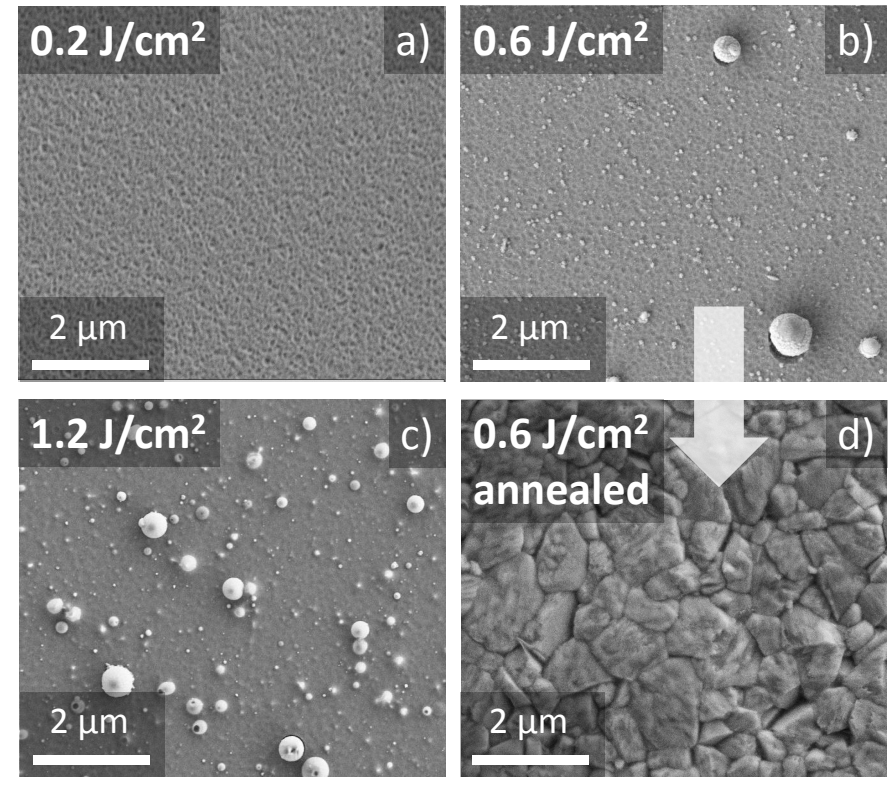

Figure 5: (a-c): top view of as-deposited films using three different laser fluences. (a) $0.2 \mathrm{~J} / \mathrm{cm}^{2}$ (low fluence); (b) $0.6 \mathrm{~J} / \mathrm{cm}^{2}$ (intermediate fluence); and (c) $1.2 \mathrm{~J} / \mathrm{cm}^{2}$ (high fluence). No peaks are detected in the XRD pattern (not shown here), indicating that the films and the droplets are amorphous. Image (d) represents film (b) after annealing in sulfurized atmosphere as used for making solar cells.

ical parameters of the different phases in the target, which are listed in Table 1. As can be seen, $\mathrm{ZnS}$ and $\mathrm{SnS}$ phases readily sublime in vacuum, either congruently ( $\mathrm{SnS})$ or incongruently $(\mathrm{ZnS})$, due to low enthalpy of evaporation. On the other

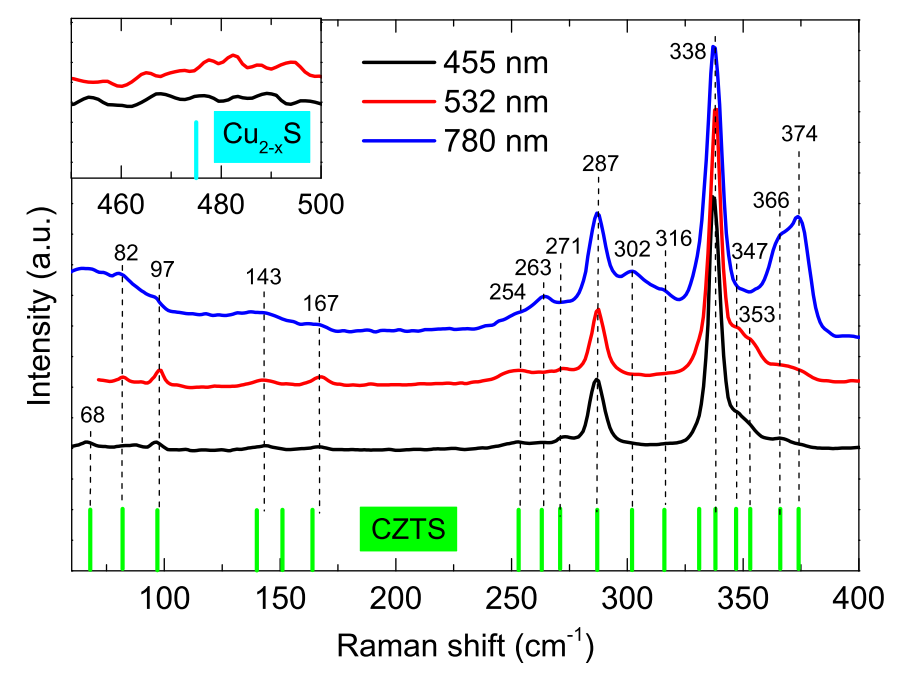

Figure 6: Raman spectra of the CZTS absorber layer at three different excitation wavelengths after annealing. All the peaks can be attributed to kesterite CZTS according to the reference peak positions taken from [29] and shown in green below the spectra. Raman spectroscopy was also performed on the bottom surface of CZTS after lift-off from the Mo substrate. No peaks related to secondary phases were found there either. The inset graph shows the spectral range where the main Raman peak of $\mathrm{Cu}_{2-\mathrm{x}} \mathrm{S}$ is expected, as indicated below the spectra. No peaks above the noise level are detected in that spectral region.

hand, $\mathrm{Cu}$-containing phases only release $\mathrm{S}_{2}$ gas when heated above the melting point, see Equations 1,2 . Only when $\mathrm{Cu}_{2} \mathrm{~S}$ is formed it can then release gaseous $\mathrm{Cu}$ after dissociation. Hence the minimum temperature for $\mathrm{Cu}$ evaporation is above the melting point of $\mathrm{Cu}_{2} \mathrm{~S}$, at $1129^{\circ} \mathrm{C}$, and the process requires more energy than $\mathrm{SnS}$ and $\mathrm{ZnS}$ sublimation. Furthermore, the specific heat of $\mathrm{ZnS}$ and $\mathrm{SnS}$ phases is lower than those of $\mathrm{Cu}-\mathrm{S}$ phases, meaning that the laser energy can be more effective in raising the local temperature of the volatile phases. $\mathrm{Cu}_{2} \mathrm{~S}$ formation from $\mathrm{CuS}$ and $\mathrm{Cu}_{1.75} \mathrm{~S}$ is a relatively energy-intensive process, which occurs through two sequential solid state reactions [24]:

$$
\begin{array}{r}
\mathrm{CuS} \rightarrow \mathrm{Cu}_{1.75} \mathrm{~S}_{(\mathrm{s})}+\mathrm{S}_{2(\mathrm{~g})} \\
\mathrm{Cu}_{1.75} \mathrm{~S}_{(\mathrm{s})} \rightarrow \mathrm{Cu}_{2} \mathrm{~S}_{(\mathrm{s})}+\mathrm{S}_{2(\mathrm{~g})}
\end{array}
$$

The enthalpies of formation of the reactions in Equations 1 and 2 are $178 \pm 4 \mathrm{~kJ} / \mathrm{mol}$ and $268 \pm 7 \mathrm{~kJ} / \mathrm{mol}$, respectively [24].

We can speculate that at very low fluence, below $0.2 \mathrm{~J} / \mathrm{cm}^{2}$, all the energy is readily absorbed by the volatile phases $\mathrm{ZnS}$ and $\mathrm{SnS}$, which very quickly dissociate and create the plasma, while the energy density on the target never reaches the critical value to dissociate $\mathrm{Cu}_{2-x} \mathrm{~S}$ phases and copper is not transferred to the films, as shown in Fig. 4(a). The relatively low heat of fusion of $\mathrm{Cu}_{2} \mathrm{~S}$ can partly explain why some of the material is not fully ablated, but instead transferred as a molten droplet when the hydrostatic pressure of the plasma on the target is enough for inducing material removal from the target. At very high fluence $\left(>0.8 \mathrm{~J} / \mathrm{cm}^{2}\right)$, we suppose that the $\mathrm{Cu}$-rich composition of the as-deposited films is a direct consequence of non-directional 


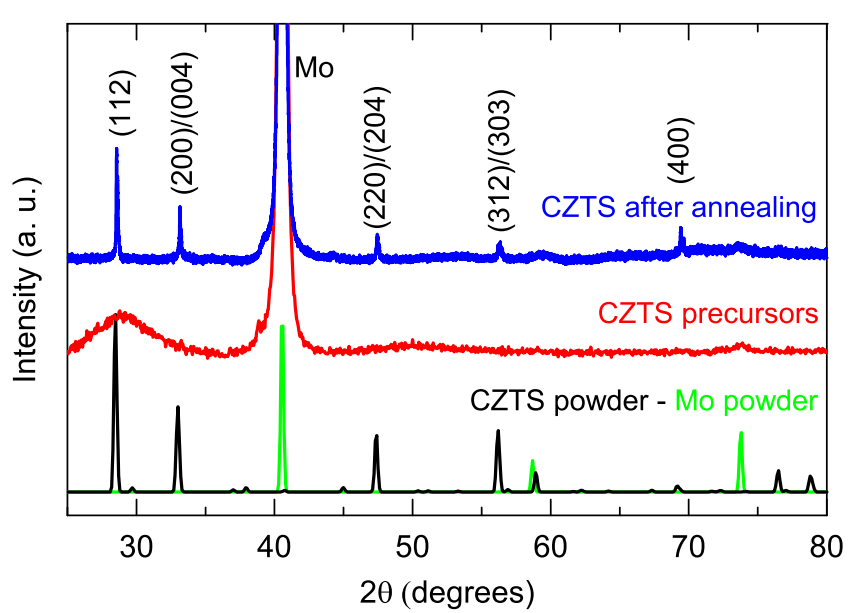

Figure 7: XRD patterns of CZTS precursors on a Mo-coated SLG substrate, and of the same precursors after annealing. All the detected peaks can be attributed either to CZTS or to Mo. The peak labels refer to the CZTS lattice planes compatible with each peak. The reference powder patterns of CZTS (black) and Mo (green) are taken from [30].

evaporation of volatile species $\mathrm{ZnS}$ and $\mathrm{SnS}$ from the target, while the ablated particles are emitted preferentially toward the substrate.

For the preparation of the solar cell absorbers we utilized precursors made at the laser fluence of $0.6 \mathrm{~J} / \mathrm{cm}^{2}$, which corresponds to Fig. 5(b). The overall composition at this fluence, estimated by $\mathrm{EDX}$, is $\mathrm{Cu}$-poor $\mathrm{Cu} /(\mathrm{Zn}+\mathrm{Sn}) \sim 0.85$, as prescribed for high efficiency CZTS devices [27]. The $\mathrm{Zn} / \mathrm{Sn}$ ratio is $\sim 1$ and the $\mathrm{S} /(\mathrm{Cu}+\mathrm{Zn}+\mathrm{Sn})$ ratio is between 0.9 and 1 . We note that the precursors in Fig. 5(b) contain $\mathrm{Cu}-\mathrm{S}$ droplets. We have verified that these droplets can be removed via $\mathrm{KCN}$ etching, but pinholes and voids are left in the precursors, which is not desirable for making solar cells. However, removal of droplets does not seem to be necessary. In fact, after the annealing process, no localized $\mathrm{Cu}$ excess is detected by EDX mapping (not shown), no traces of secondary phases are visually evident by SEM (Fig. 5(d)), and no $\mathrm{Cu}_{2-x} \mathrm{~S}$ is detected by Raman spectroscopy (inset of Fig. 6). This indicates that the $\mathrm{Cu}$ atoms diffuse effectively in the film during annealing.

While the XRD pattern of CZTS precursors only exhibits a very broad hump around the (112) reflection (Fig. 7), the XRD pattern after annealing consists of several narrow peaks, which indicates formation of large crystals grains upon annealing in accordance with the SEM images in Fig. 5. All XRD peaks can be attributed to kesterite CZTS or related zincblende phases $\mathrm{ZnS}$ or $\mathrm{Cu}_{2} \mathrm{SnS}_{3}$ (Fig. 7). The 16 Raman peaks identified in the same sample are a signature of kesterite CZTS (Fig. 6). Raman spectroscopy was also performed on the bottom surface of CZTS after lift-off from the Mo substrate. No peaks related to secondary phases were found there either.

\subsection{Solar cell characterization}

\subsubsection{Morphology and thickness}

In Fig. 8 a SEM cross section of our champion device with $5.2 \%$ active area efficiency is shown. The morphology is com-

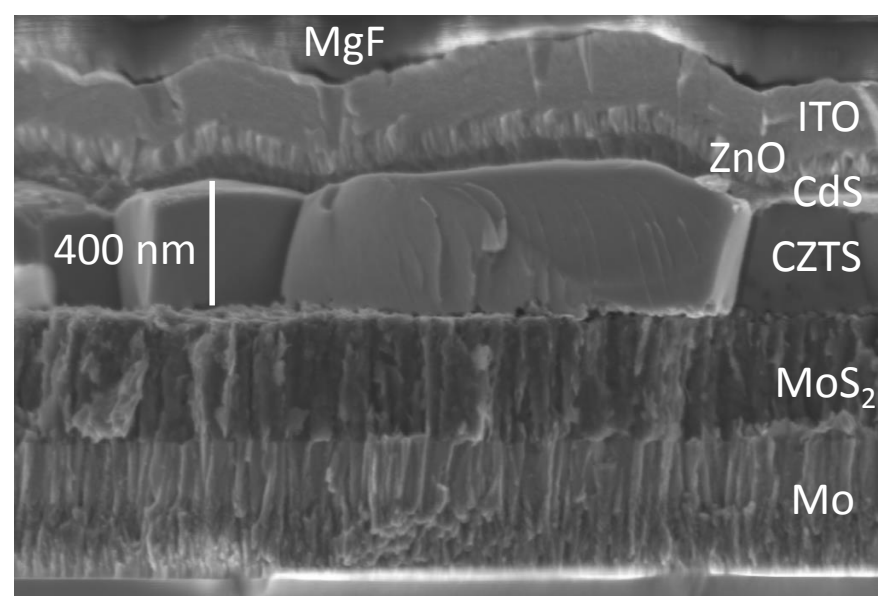

Figure 8: SEM image of the cross section of our champion device.

pact and most grains extend from bottom to top. No obvious segregation of smaller grains and secondary phases exists at the interfaces, and no voids are visible, in contrast to what is often observed even in state-of-the-art devices [9, 31]. We emphasize that these features are common to all our annealed films, regardless of the specific point where the image is taken. Since all Raman and XRD peaks are attributable to CZTS (Figs. 6,7), the volume fraction of any secondary phase is below the detection limit of those techniques. We speculate that the absence of voids and secondary phases in the annealed films may be a consequence of the compact and amorphous structure of the precursors obtained by PLD. This hypothesis is based on the outcome of previous studies [32, 33], which indicate that formation of large CZTS crystals occurs more rapidly from amorphous precursors than from already crystallized precursors. Interestingly, sputtered CZTS precursors often show a more crystalline structure compared to our PLD precursors [31, 34]. This is probably due to a negligible heat transfer from the impinging species to the growing film in the case of PLD [16] and may explain why sputtered CZTS often contains a detectable fraction of secondary phases after annealing [31,35].

We suppose that the formation of a relatively thick $\mathrm{MoS}_{2}$ layer in our solar cell is related to the closed annealing system used to sulfurize CZTS precursors. There, the gaseous sulfur supply provided by sulfur powder can remain in the annealing atmosphere for a longer time than in a conventional two-zone furnace based on a sulfur flow. Thus, a larger fraction of the Mo film is sulfurized. The SEM image in Fig. 8 was taken about 2-3 $\mathrm{mm}$ from the solar cell area and, with a conservative estimate on the expected thickness gradient, the CZTS layer in the solar cell does not exceed a thickness of $450 \mathrm{~nm}$, which is among the lowest values reported for high efficiency CZTS devices [15, 31]. Unfortunately, we were not able to obtain a higher efficiency by just increasing the CZTS thickness. This is because attempts to produce large-grained CZTS films thicker than about $600 \mathrm{~nm}$ failed due to delamination of CZTS from $\mathrm{MoS}_{2}$ upon annealing. The origin of this phenomenon is currently being investigated.

Chalcogenide absorbers below $700 \mathrm{~nm}$ thickness are some- 


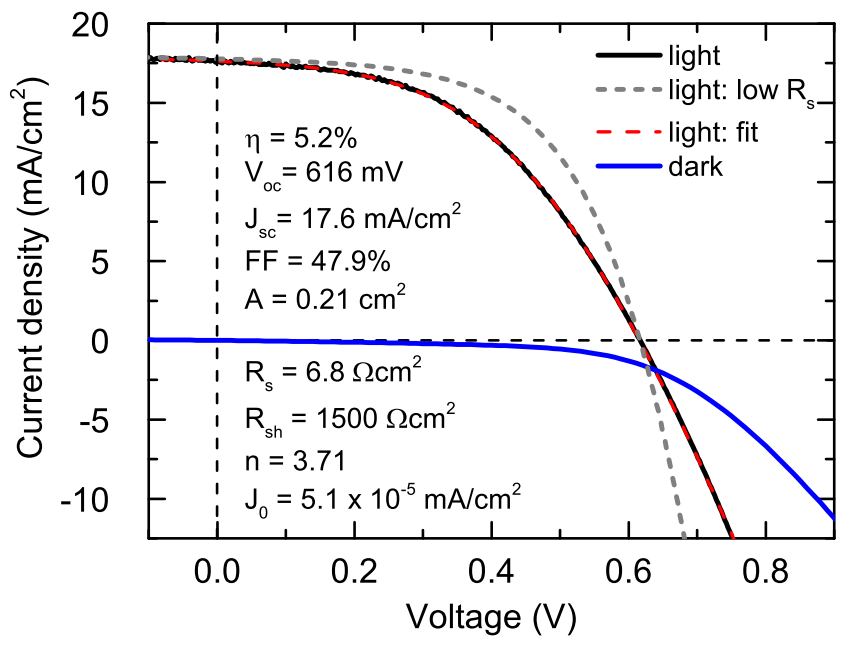

Figure 9: The dark and illuminated (1 sun) J-V curve of our champion device fitted with a single diode model (red dashed curve). All parameters, with the exception of the dark saturation current density $J_{0}$, were extracted by fitting the illuminated J-V curve. The high series resistance is due to non-ideal top contact geometry, as discussed in Section 3.3.3. Assuming a series resistance of $1 \Omega \mathrm{cm}^{2}$ (grey dashed curve), the fill factor and efficiency increase to $58 \%$ and $6.3 \%$, respectively.

times referred to as "ultra-thin" in the literature [36, 37]. In general, if the material properties of the absorber were independent of thickness, one would expect only the short circuit current to be reduced in an ultra-thin absorber, due to 1) incomplete light absorption, and 2) lower collection efficiency, as more minority carriers are generated near the back contact where they can recombine. However, keeping a high material quality in ultra-thin absorbers has been proven to be very challenging for CdTe [36], CIGS [38] and CZTS [31]. Even though back contact recombination can be successfully reduced by introduction of a back surface passivation layer [38], device efficiencies at thicknesses below $500 \mathrm{~nm}$ are still consistently lower than expected from short circuit current losses alone [36]. In fact, in all the above studies there was a noticeable decrease in both the open circuit voltage and the fill factor. A common observation was that the morphology of ultra-thin absorbers was inferior to that of thicker films grown under the same conditions, mainly in terms of reduced grain size and increased density of shunt paths. While it is difficult to evaluate the effect of the former on device efficiency, the latter is documented by a decrease of the device shunt resistance with decreasing thickness [31, 36, 38]. The only systematic investigation of CZTS thickness effects on device efficiency was done for co-sputtered CZTS [31]. There, the effect was particularly strong: a $500 \mathrm{~nm}$ absorber achieved only $50 \%$ of the efficiency of a $2 \mu \mathrm{m}$ absorber, compared to $80 \%$ for both CdTe and CIGS $[36,38]$. This was attributed to the increasing role played by secondary phases $(\mathrm{SnS}, \mathrm{ZnS})$, both at the front and back interface of CZTS. In the following section these issues will be quantified in our own device.

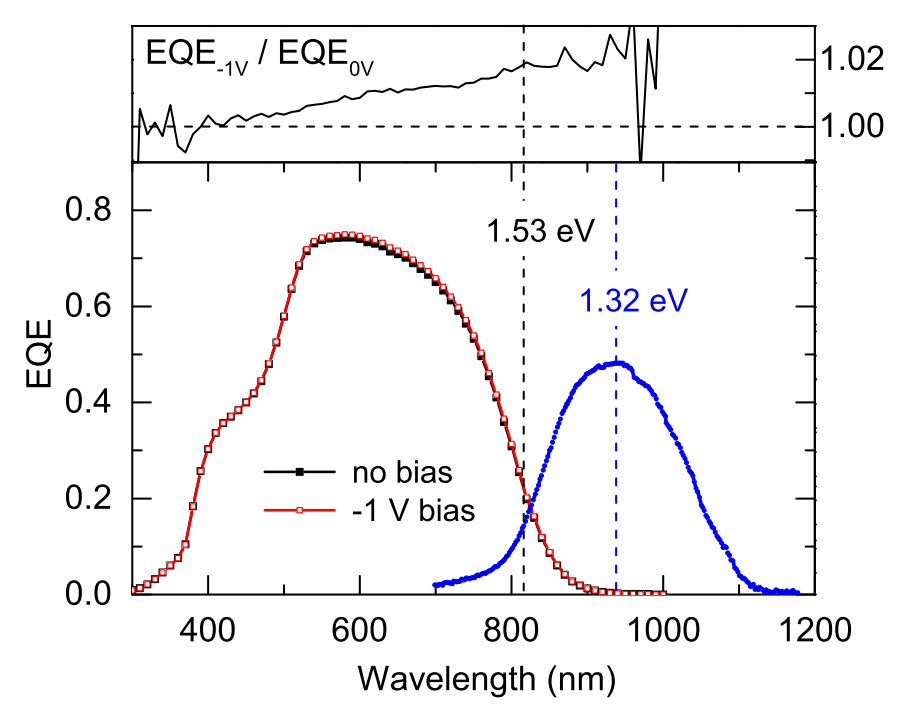

Figure 10: External Quantum Efficiency curves under $0 \mathrm{~V}$ bias (black symbols) and $-1 \mathrm{~V}$ bias (red symbols). The inflection point of the $\mathrm{EQE}_{0 \mathrm{~V}}(\lambda)$ curve at $810 \mathrm{~nm}(1.53 \mathrm{eV})$ is indicated with a black dashed line. The inset shows the ratio $\mathrm{EQE}_{-1 \mathrm{~V}}(\lambda) / \mathrm{EQE}_{0 \mathrm{~V}}(\lambda)$. The PL spectrum at room temperature of the finished device (blue symbols) has a maximum at $1.32 \mathrm{eV}$ (blue dashed line).

\subsubsection{Electrical and optical properties}

The dark and illuminated (1 sun) J-V curves, steady state PL, and EQE (at zero and reverse bias) are shown in Figs. 9 and 10. The CZTS band gap of $1.53 \mathrm{eV}$, indicated in Fig. 10, corresponds to to the inflection point of the EQE curve. The PL spectrum has a peak at a lower energy $(1.32 \mathrm{eV})$, similarly to previous investigations on CZTS devices $[9,39]$. This is believed to be due to a high density of band-edge tail states that reduces the achievable open circuit voltage [26].

The short circuit current $J_{\mathrm{sc}}=17.6 \mathrm{~mA} / \mathrm{cm}^{2}$ derived from the illuminated $\mathrm{J}-\mathrm{V}$ curve is in good agreement with the value of $17.4 \mathrm{~mA} / \mathrm{cm}^{2}$ obtained by integration of the EQE measured under white light bias. Despite the very thin absorber, this is a fairly high value for CZTS solar cells, which hints to a high collection efficiency, as will be discussed later. The shunt resistance $R_{\mathrm{sh}}$ and the dark saturation current $J_{0}$ are also comparable to state-of-the-art CZTS devices with larger thickness and efficiency $>7 \%[4,6,7,9]$. The high shunt resistance is consistent with the absence of voids and shunting paths as revealed by SEM imaging (Fig. 8). On the other hand, the open circuit voltage $V_{\mathrm{oc}}=616 \mathrm{mV}$ is somewhat lower and the fill factor $F F=47.9 \%$ is much lower than in benchmark devices. The latter is mostly due to high series resistance $R_{s}$ and a high diode ideality factor $n$.

As mentioned above, short circuit current losses are always expected in ultra-thin absorbers, so it can be instructive to quantify them. The calculated losses due to incomplete light absorption are reported in Fig. 11 and explained in the caption. The potential gain in short circuit current by complete light absorption due to the extra generated carriers is not negligible $(+1.9$ $\mathrm{mA} / \mathrm{cm}^{2}$ ). This could be achieved either by a thicker absorber, 


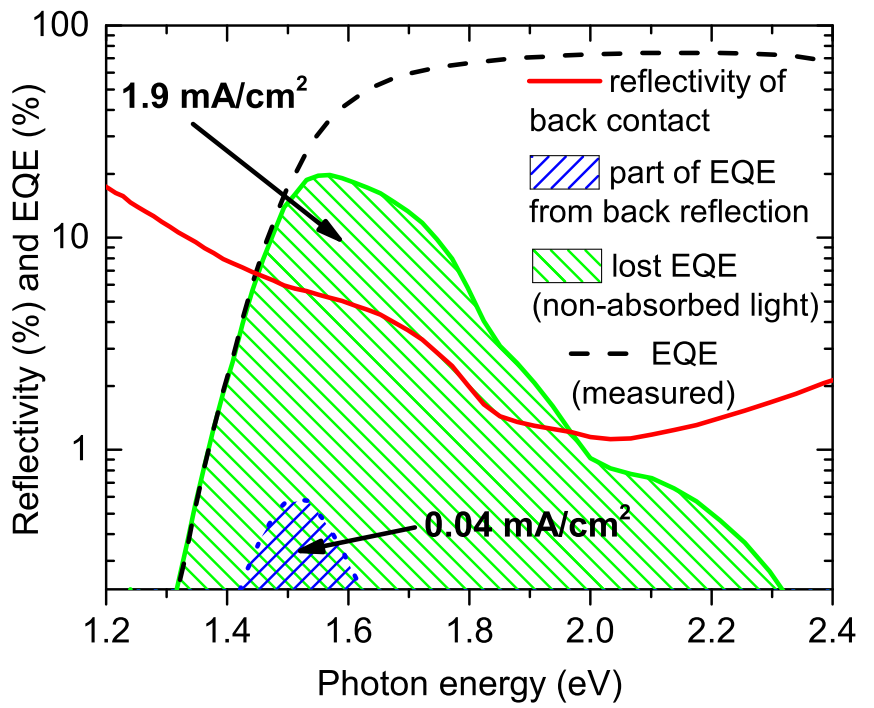

Figure 11: Calculated losses on the short circuit current due to the limited thickness of the device. In dashed green the current loss due to non absorbed light (assuming 90\% collection efficiency). In dashed blue the contribution to current gain from reflection at the $\mathrm{CZTS} / \mathrm{MoS}_{2}$ interface. Note the logarithmic scale. The solid red curve is the calculated reflectivity of the back contact, which includes contributions from a single CZTS-MoS 2 reflection and a single $\mathrm{MoS}_{2}$-Mo reflection minus absorbtion in the $\mathrm{MoS}_{2}$ layer. The optical functions of CZTS, $\mathrm{MoS}_{2}$ and Mo were taken from the literature [40, 41]. The thickness of $\mathrm{MoS}_{2}$ in the calculation is $390 \mathrm{~nm}$ as in our solar cell. The reflectivities of the two interfaces were calculated using the Fresnel reflection coefficient.

or by an ideal back reflector, and would result in a $10 \%$ relative gain in efficiency, up to $5.7 \%$. The $J_{\text {sc }}$ would then be close to $20 \mathrm{~mA} / \mathrm{cm}^{2}$, which is comparable to the state-of-the-art CZTS solar cells [4, 6, 7, 9].

However, with our back contact structure (390 nm $\mathrm{MoS}_{2} / \mathrm{Mo}$ ), the calculated contribution of back contact reflection to the short circuit current is as low as $0.04 \mathrm{~mA} / \mathrm{cm}^{2}$, which is negligible. This difference can be explained as follows. The reflection at the CZTS/MoS $\mathrm{M}_{2}$ interface is negligible due to the small mismatch between the optical functions of the two materials. While the $\mathrm{MoS}_{2}$ /Mo reflectivity is higher (about 20\% in the high wavelength range), still the remaining $80 \%$ is completely absorbed in the Mo and there is a large additional contribution from absorption in the thick $\mathrm{MoS}_{2}$ layer. Even if the $\mathrm{MoS}_{2}$ was only $50 \mathrm{~nm}$ thick, the contribution of back contact reflection would still be relatively low $\left(0.3 \mathrm{~mA} / \mathrm{cm}^{2}\right)$. In the limiting case of a direct CZTS/Mo interface, the contribution would increase slightly to $0.5 \mathrm{~mA} / \mathrm{cm}^{2}$.

The fact that our measured short circuit current, corrected for optical losses due to finite thickness, is comparable to stateof-the-art CZTS devices, points to the fact that collection efficiency is reasonably high and not significantly degraded by the small thickness of the absorber. To confirm this hypothesis, we investigated the ratio between the EQE at zero voltage bias $\left(\mathrm{EQE}_{0 \mathrm{~V}}\right)$ and at $-1 \mathrm{~V}$ reverse bias $\left(\mathrm{EQE}_{-1 \mathrm{~V}}\right)$ of our

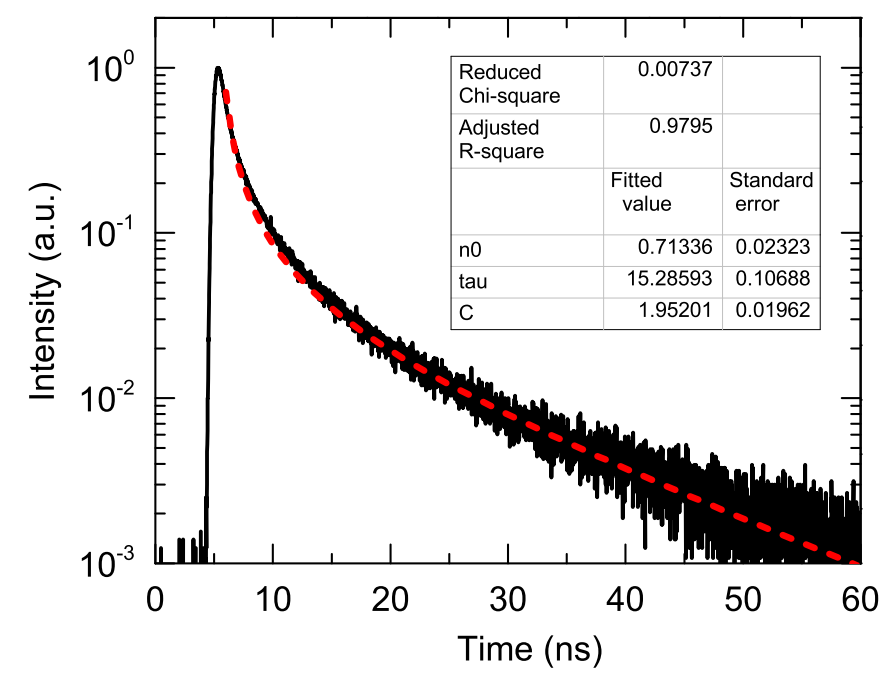

Figure 12: Time-resolved photoluminescence of a bare CZTS film after annealing. The red dashed line is the fit following Equation 4 with the coefficients $n_{0}, \tau$, and $C$ as indicated in the figure.

device, as shown in the upper panel of Fig. 10. Remarkably, the two curves never differ by more than $2 \%$ for photon energies above the CZTS band gap and the difference steadily reduces at shorter wavelengths. This resembles closely the measurement in [9], where the maximum difference in EQE at $0 \mathrm{~V}$ and $-1 \mathrm{~V}$ was slightly more than $3 \%$ for a $600 \mathrm{~nm}$-thick, $8.4 \%$-efficient device. In [31], a deviation of more than $10 \%$ was observed even at a reverse bias of only $-0.5 \mathrm{~V}$, indicating dramatic problems with collection efficiency attributed by the authors to secondary phases at the interfaces. These results suggest that our device is relatively unaffected by collection losses, and that the diffusion length $\mathrm{L}_{d}$ of minority carriers is larger than the quasineutral region $\mathrm{W}_{N}$ of our absorber. We attribute the small increase in EQE at reverse bias to back surface recombination losses that are inevitable for a thin absorber in the absence of a back surface field.

A diffusion length greater than the quasi-neutral region, $L_{\mathrm{D}}>$ $W_{\mathrm{N}}$, is also supported by the analysis of time-resolved photoluminescence (TR-PL), as illustrated in Fig. 12. The TR-PL signal does not follow a simple exponential decay and is best described by a rate equation which contains both a linear and a quadratic term in the excess carrier density $n$ :

$$
\frac{d n}{d t}=-A n-C n^{2}
$$

Following [42], and substituting $A=1 / \tau$ for the linear term, which represents the minority-carrier lifetime in the low injection regime, the solution to Equation 3 is:

$$
n(t)=\frac{n_{0} \exp (-t / \tau)}{1+n_{0} C \tau[1-\exp (-t / \tau)]}
$$

By fitting the whole range of the PL decay according to this model, we obtain a value of about $15 \mathrm{~ns}$ for the carrier lifetime. We note that, if the same fitting method as [9] is applied, we obtain about $10 \mathrm{~ns}$ lifetime. While carrier lifetimes reported in the 
literature cannot always be compared directly due to the different models used by different authors to fit the TR-PL data, we emphasize that this value is at the high end for CZTS absorbers [9].

To provide a lower bound value for the minority carrier diffusion length, we estimate the width of the depletion region by means of C-V scan measurements. In Fig. 13 we show the density of charged states at different depths into the CZTS absorber, which constitutes an upper limit to its real doping density. The plot has been derived from $\mathrm{C}-\mathrm{V}$ scans by applying a standard model for a $\mathrm{p}-\mathrm{n}^{+}$junction, where all the measured capacitance is due to ionized acceptors in the depletion region, which is assumed to extend exclusively in the p-type absorber. Due to the significant series resistance present in the device, we corrected the measured capacitance and conductance at each DC voltage bias based on an equivalent circuit with an $\mathrm{AC}$ resistance in series with the junction [43]. The value of the AC resistance was estimated as $8.1 \Omega \mathrm{cm}^{2}$ from the characteristics of the capacitance decline at high frequency in a separate capacitancefrequency (C-f) measurement. The resulting charged state density stabilizes to about $3 \times 10^{16} \mathrm{~cm}^{-3}$ within the depletion region, which is interpreted as an upper limit for the true doping density of CZTS. Outside the depletion region, the charged state density seems to increase rapidly. We believe this to be a data analysis artifact due to the simplified model for the device response to the $\mathrm{C}-\mathrm{V}$ measurement. Indeed, in thin-film materials trap states can be an additional sources of capacitance besides the ionized shallow acceptors. [44]. Following [43], the width of the depletion region at zero bias $W_{\mathrm{D}}$ is estimated to be $190 \mathrm{~nm}$, similarly to that in Ref. [9]. However, this value is obtained under the strong assumptions that both the $\mathrm{CdS}$ and the $\mathrm{i}-\mathrm{ZnO}$ layers are much more heavily doped than the CZTS absorber, which is questionable $[45,46]$. In the case of a completely depleted 60 nm-thick CdS layer, the depletion region width in CZTS can be extracted by assuming the measured capacitance $C_{\mathrm{m}}$ to be due to two equivalent capacitors in series: one encompasses the full $\mathrm{CdS}$ buffer layer $\left(C_{\mathrm{b}}\right)$, and the other is due to the depletion region of the CZTS absorber $\left(C_{\mathrm{a}}\right)$, so that:

$$
\frac{1}{C_{\mathrm{m}}}=\frac{1}{C_{\mathrm{a}}}+\frac{1}{C_{\mathrm{b}}}
$$

Here $C_{\mathrm{a}}=\varepsilon_{0} \varepsilon_{\mathrm{a}} \Sigma / W_{\mathrm{D}}$ and $C_{\mathrm{b}}=\varepsilon_{0} \varepsilon_{\mathrm{b}} \Sigma / d$, where $\varepsilon_{0}$ is the vacuum permittivity, $\varepsilon_{a}\left(\varepsilon_{b}\right)$ is the relative permittivity of the absorber (buffer) layer, $\Sigma$ is the solar cell area, and $d$ is the thickness of the buffer layer. Under these assumptions, the extracted CZTS depletion region width reduces to $150 \mathrm{~nm}$, and further to $110 \mathrm{~nm}$ if both the $\mathrm{CdS}$ and the $\mathrm{i}-\mathrm{ZnO}$ layers are assumed to be completely depleted. Hence, we estimate an interval from 110 to $190 \mathrm{~nm}$ for the depletion width in CZTS. From this we conclude that the minority carrier diffusion length must be at least $300 \mathrm{~nm}$. Indeed, if the diffusion length is simply calculated using the measured lifetime of $15 \mathrm{~ns}$ and a CZTS electron mobility of $3 \mathrm{~cm}^{2} / \mathrm{Vs}$ [47], the result is $350 \mathrm{~nm}$.

\subsubsection{Performance limitations}

The main deficit of our device with respect to state-of-the-art CZTS solar cells is the low fill factor of $47.9 \%$, which is due

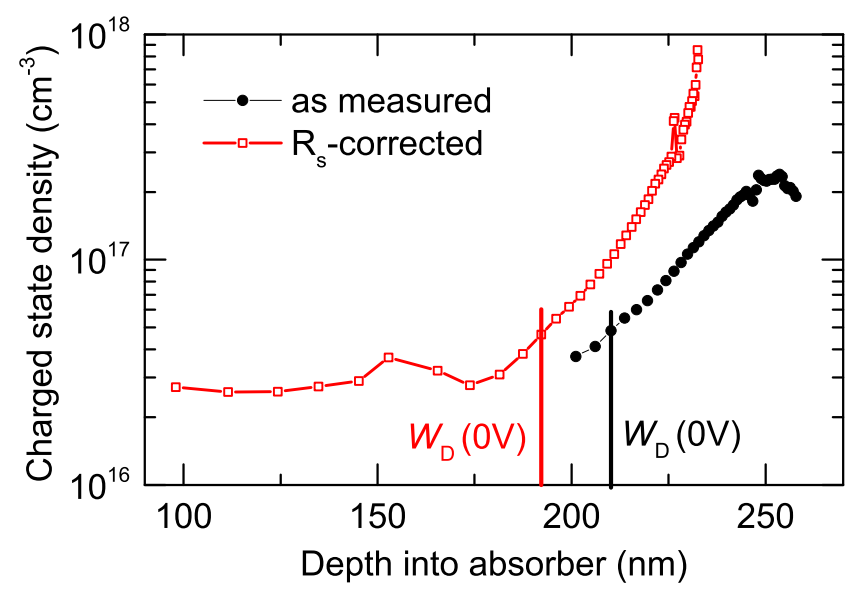

Figure 13: Depth profile of the density of charged states in the CZTS absorber extracted from a capacitance-voltage measurement. Black filled symbols: uncorrected data assuming zero series resistance. Open red symbols: data corrected for an AC series resistance of $8.1 \Omega \mathrm{cm}^{2}$. $W_{\mathrm{D}}$ is the width of the depletion region at zero bias, assuming that the $\mathrm{CdS}$ and $\mathrm{i}-\mathrm{ZnO}$ layers have much heavier doping than CZTS.

to a high ideality factor and high series resistance. To investigate the possible origin of the latter, we studied the dependence of series resistance on device area. This was done on an adjacent solar cell on the same chip (with similar series resistance) by measuring its dark $\mathrm{J}-\mathrm{V}$ characteristic after reducing its total area $A$ by mechanical scribing. Four scribing-measurement iterations were performed. As shown in Fig. 14, the series resistance of the solar cell increases linearly with area. Hence, we conclude that the main contribution to the high series resistance must be the lateral spreading resistance of the ITO layer. By proper design of a top contact grid, this contribution can be minimized with a minimal loss in short circuit current due to shadowing. Therefore, we plotted in Fig. 9 also the simulated $\mathrm{J}-\mathrm{V}$ curve under illumination with the same parameters of the fitted experimental J-V curve but a lower realistic series resistance of $1 \Omega \mathrm{cm}^{2}$. As a result the fill factor improves up to a value of $58 \%$, close to the values reported for state-of-the-art CZTS solar cells, which would lead to a device efficiency of $6.3 \%$ (Fig. 9).

The origin of the high ideality factor can only be speculated at the moment. However, it was observed in a study on ultrathin CdTe solar cells [48] that the ideality factor increased with decreasing absorber thickness, up to a value of 3.9 for a thickness of $500 \mathrm{~nm}$. The authors attributed the fact to voltagedependent collection in the thin solar cell. This explanation may apply to our device as well, since our estimated collection depth is not much larger than the thickness of the absorber. This implies that significant collection losses may occur under forward bias, where the depletion region shrinks.

The $\mathrm{V}_{\mathrm{oc}}$ of our device is inferior to [9] by about $50 \mathrm{mV}$. Since our carrier lifetimes are relatively high, this discrepancy could be due to enhanced back surface recombination in the thin absorber, or alternatively to a voltage-dependent collection efficiency under forward bias as proposed above. 


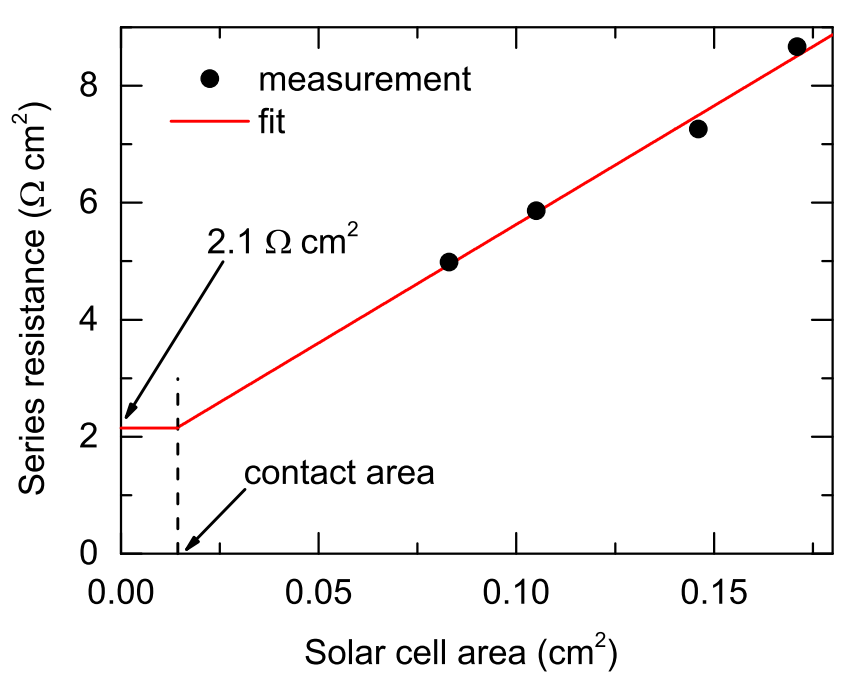

Figure 14: Dependance of dark series resistance on device area, with a linear fit to the measured points. The area of the silver paste dot contact is $0.015 \mathrm{~cm}^{2}$. The area-independent dark series resistance is extrapolated as $2.1 \Omega \mathrm{cm}^{2}$. This corresponds to the case where the lateral spreading resistance of the ITO layer is no longer the limiting factor for the series resistance.

\section{Conclusion}

We reported a pure-sulfide CZTS solar cell device with 5.2\% active area efficiency using an ultra-thin absorber $(<450 \mathrm{~nm})$ prepared by pulsed laser deposition. Careful control of the laser fluence allows deposition of high-quality amorphous CZTS precursors with the optimal stoichiometry for solar cells. Such precursors do not result in detectable segregation of secondary phases in the subsequent annealing step. We believe this is the main reason why the present device performs well compared to previously reported CZTS devices of similar thickness. Unfortunately, delamination of CZTS from its back contact has so far prevented us from improving the solar cell efficiency by increasing the CZTS layer thickness. Encouragingly, materialand junction quality in the ultra-thin absorber are comparable to those found in thicker state-of-the-art absorbers: grain size, carrier lifetimes, collection efficiency, shunt resistance, and dark saturation current are all similar to benchmark CZTS solar cells. There is an appreciable fill factor deficit compared to the benchmark cells, which however does not appear to be a thicknessrelated effect. Instead, it is mostly due to non-optimal contact geometry, which should not represent a severe development roadblock. The short circuit current in the ultra-thin device differs from that of full-thickness CZTS devices just by optical losses $\left(<2 \mathrm{~mA} / \mathrm{cm}^{2}\right)$ due to incomplete light absorption. Light trapping from a nano-structured back contact may prevent those losses and will be the subject of future work.

\section{Acknowledgements}

This work was supported by a grant from the Danish Council for Strategic Research, from VILLUM Fonden (grant 9455), and from the Australian Government through the Australian Renewable Energy Agency (ARENA) (1-USO028) and Australian Research Council (ARC) (DP)(DP120103097). The authors are grateful to Fangzhou Zhou (UNSW) for assistance with device fabrication and packaging, to Fangyang Liu (UNSW) for assistance with efficiency measurement, and to John Stride (UNSW) for lab access. A. Crovetto acknowledges the Nanocarbon and Nanoprobes groups (DTU Nanotech) for usage of the Raman setup.

\section{References}

\section{References}

[1] K. Ito, Copper Zinc Tin Sulfide-Based Thin-Film Solar Cells, Wiley, 2015.

[2] X. Liu, Y. Feng, H. Cui, F. Liu, X. Hao, G. Conibeer, D. B. Mitzi, M. Green, The current status and future prospects of kesterite solar cells: a brief review, Progress in Photovoltaics: Research and Applicationsdoi:10.1002/pip. 2741 .

[3] W. Wang, M. T. Winkler, O. Gunawan, T. Gokmen, T. K. Todorov, Y. Zhu, D. B. Mitzi, Device Characteristics of CZTSSe Thin-Film Solar Cells with 12.6\% Efficiency, Advanced Energy Materials 4 (7) (2013) 1301465. doi:10.1002/aenm.201301465.

[4] S. Tajima, T. Itoh, H. Hazama, K. Ohishi, R. Asahi, Improvement of the open-circuit voltage of $\mathrm{Cu}_{2} \mathrm{ZnSnS}_{4}$ solar cells using a two-layer structure, Applied Physics Express 8 (8) (2015) 082302. doi:10.7567/APEX.8.082302.

[5] P. Jackson, D. Hariskos, R. Wuerz, O. Kiowski, A. Bauer, T. M. Friedlmeier, M. Powalla, Properties of $\mathrm{Cu}(\mathrm{In}, \mathrm{Ga}) \mathrm{Se}_{2}$ solar cells with new record efficiencies up to $21.7 \%$, physica status solidi (RRL) - Rapid Research Letters 9 (1) (2015) 28-31. doi:10.1002/pssr.201409520.

[6] K. Sun, C. Yan, F. Liu, J. Huang, F. Zhou, J. A. Stride, M. Green, X. Hao, Over $9 \%$ Efficient Kesterite $\mathrm{Cu}_{2} \mathrm{ZnSnS}_{4}$ Solar Cell Fabricated by Using $\mathrm{Zn}_{1-x} \mathrm{Cd}_{x} \mathrm{~S}$ Buffer Layer, Advanced Energy Materials 6 (12) (2016) 1600046. doi:10.1002/aenm.201600046.

[7] J. J. Scragg, T. Kubart, J. T. Wätjen, T. Ericson, M. K. Linnarsson, C. Platzer-Björkman, Effects of Back Contact Instability on $\mathrm{Cu}_{2} \mathrm{ZnSnS}_{4}$ Devices and Processes, Chemistry of Materials 25 (15) (2013) 31623171. doi: $10.1021 / \mathrm{cm} 4015223$.

[8] A. Fairbrother, X. Fontané, V. Izquierdo-Roca, M. Espíndola-Rodríguez, S. López-Marino, M. Placidi, L. Calvo-Barrio, A. Pérez-Rodríguez, E. Saucedo, On the formation mechanisms of $\mathrm{Zn}$-rich $\mathrm{Cu}_{2} \mathrm{ZnSnS}_{4}$ films prepared by sulfurization of metallic stacks, Solar Energy Materials and Solar Cells 112 (2013) 97-105. doi:10.1016/j.solmat.2013.01.015.

[9] B. Shin, O. Gunawan, Y. Zhu, N. A. Bojarczuk, S. J. Chey, S. Guha, Thin film solar cell with $8.4 \%$ power conversion efficiency using an earthabundant $\mathrm{Cu}_{2} \mathrm{ZnSnS}_{4}$ absorber, Progress in Photovoltaics: Research and Applications 21 (1) (2013) 72-76. doi:10.1002/pip.1174.

[10] K. Wang, O. Gunawan, T. Todorov, B. Shin, S. J. Chey, N. A. Bojarczuk, D. Mitzi, S. Guha, Thermally evaporated $\mathrm{Cu}_{2} \mathrm{ZnSnS}_{4}$ solar cells, Applied Physics Letters 97 (14) (2010) 143508. doi:10.1063/1.3499284.

[11] T. Mise, S. Tajima, T. Fukano, K. Higuchi, T. Washio, K. Jimbo, H. Katagiri, Improving the photovoltaic performance of co-evaporated $\mathrm{Cu}_{2} \mathrm{ZnSnS}_{4}$ thin-film solar cells by incorporation of sodium from $\mathrm{NaF}$ layers, Progress in Photovoltaics: Research and Applications (2016) n/an/adoi:10.1002/pip. 2745.

[12] B.-A. Schubert, B. Marsen, S. Cinque, T. Unold, R. Klenk, S. Schorr, H.-W. Schock, $\mathrm{Cu}_{2} \mathrm{ZnSnS}_{4}$ thin film solar cells by fast coevaporation, Progress in Photovoltaics: Research and Applications 19 (1) (2011) 9396. doi:10.1002/pip.976.

[13] K. Moriya, K. Tanaka, H. Uchiki, Fabrication of $\mathrm{Cu}_{2} \mathrm{ZnSnS}_{4}$ Thin-Film Solar Cell Prepared by Pulsed Laser Deposition, Japanese Journal of Applied Physics 46 (9A) (2007) 5780-5781. doi:10.1143/JJAP.46.5780.

[14] K. Moriya, K. Tanaka, H. Uchiki, $\mathrm{Cu}_{2} \mathrm{ZnSnS}_{4}$ Thin Films Annealed in H 2 S Atmosphere for Solar Cell Absorber Prepared by Pulsed Laser Deposition, Japanese Journal of Applied Physics 47 (1) (2008) 602-604. doi:10.1143/JJAP.47.602. 
[15] X. Jin, C. Yuan, L. Zhang, G. Jiang, W. Liu, C. Zhu, Pulsed laser deposition of $\mathrm{Cu}_{2} \mathrm{ZnSn}\left(\mathrm{S}_{\mathrm{X}} \mathrm{Se}_{1-\mathrm{x}}\right)_{4}$ thin film solar cells using quaternary oxide target prepared by combustion method, Solar Energy Materials and Solar Cells 155 (2016) 216-225. doi:10.1016/j.solmat.2016.06.022.

[16] P. R. Willmott, Deposition of complex multielemental thin films, Progress in Surface Science 76 (6-8) (2004) 163-217. doi:10.1016/j.progsurf.2004.06.001.

[17] D. Norton, Pulsed Laser Deposition of complex materials: Progress towards applications, in: R. Eason (Ed.), Pulsed Laser Deposition of Thin Films, John Wiley \& Sons, Inc., Hoboken, NJ, USA, 2008, pp. 3-31. doi:10.1002/0470052120.

[18] M. Frumar, B. Frumarova, P. Nemec, T. Wagner, J. Jedelsky, M. Hrdlicka, Thin chalcogenide films prepared by pulsed laser deposition - new amorphous materials applicable in optoelectronics and chemical sensors, Journal of Non-Crystalline Solids 352 (6) (2006) 544-561. doi:10.1016/j.jnoncrysol.2005.11.043.

[19] H. Krebs, Characteristic properties of laser-deposited metallic systems, International Journal of Non-equilibrium Processing 10 (1) (1997) 3-24.

[20] T. Ohnishi, M. Lippmaa, T. Yamamoto, S. Meguro, H. Koinuma, Improved stoichiometry and misfit control in perovskite thin film formation at a critical fluence by pulsed laser deposition, Applied Physics Letters 87 (24) (2005) 1-3. doi:10.1063/1.2146069.

[21] H. Dittrich, M. Klose, M. Brieger, R. Schaffler, H. Schock, CuInSe thin film solar cells by pulsed laser deposition, in: Conference Record of the Twenty Third IEEE Photovoltaic Specialists Conference - 1993 (Cat. No.93CH3283-9), IEEE, 1993, pp. 617-620. doi:10.1109/PVSC.1993.347022.

[22] C. Yan, F. Liu, K. Sun, N. Song, J. A. Stride, F. Zhou, X. Hao, M. Green, Boosting the efficiency of pure sulfide CZTS solar cells using the In/Cdbased hybrid buffers, Solar Energy Materials and Solar Cells 144 (2016) 700-706. doi:10.1016/j.solmat.2015.10.019.

[23] V. Piacente, S. Foglia, P. Scardala, Sublimation study of the tin sulphides $\mathrm{SnS}_{2}, \mathrm{Sn}_{2} \mathrm{~S}_{3}$ and $\mathrm{SnS}$, Journal of Alloys and Compounds 177 (1) (1991) 17-30. doi:10.1016/0925-8388(91)90053-X.

24] B. Brunetti, V. Piacente, P. Scardala, Study on sulfur vaporization from covellite $(\mathrm{CuS})$ and anilite $\left(\mathrm{Cu}_{1.75} \mathrm{~S}\right)$, Journal of Alloys and Compounds 206 (1) (1994) 113-119. doi:10.1016/0925-8388(94)90018-3.

[25] W. M. Haynes, CRC Handbook of Chemistry and Physics, 96th Edition, CRC Press, 2015.

[26] T. Gokmen, O. Gunawan, T. K. Todorov, D. B. Mitzi, Band tailing and efficiency limitation in kesterite solar cells, Applied Physics Letters 103 (10) (2013) 103506. doi:10.1063/1.4820250.

[27] H. Katagiri, Survey of development of CZTS-based thin film solar cells, in: 2012 IEEE 3rd International Conference on Photonics, IEEE, 2012 pp. 345-349. doi:10.1109/ICP.2012.6379533.

[28] R. B. Ettlinger, A. Crovetto, S. Canulescu, A. Cazzaniga, L. Ravnkilde, T. Youngman, O. Hansen, N. Pryds, J. Schou, Formation of copper tin sulfide films by pulsed laser deposition at 248 and $355 \mathrm{~nm}$, Applied Physics A 122 (4) (2016) 466. doi:10.1007/s00339-016-9939-4.

[29] M. Dimitrievska, A. Fairbrother, X. Fontané, T. Jawhari, V. IzquierdoRoca, E. Saucedo, A. Pérez-Rodríguez, Multiwavelength excitation Raman scattering study of polycrystalline kesterite $\mathrm{Cu}_{2} \mathrm{ZnSnS}_{4}$ thin films, Applied Physics Letters 104 (2) (2014) 021901. doi:10.1063/1.4861593.

[30] icsd.fiz-karlsruhe.de. Collection codes: 239674 (CZTS), 173127 (Mo).

[31] Y. Ren, J. J. S. Scragg, C. Frisk, J. K. Larsen, S.-Y. Li, C. PlatzerBjörkman, Influence of the $\mathrm{Cu}_{2} \mathrm{ZnSnS}_{4}$ absorber thickness on thin film solar cells, physica status solidi (a) 212 (12) (2015) 2889-2896. doi:10.1002/pssa.201532311.

[32] R. Mainz, B. C. Walker, S. S. Schmidt, O. Zander, A. Weber, H. Rodriguez-Alvarez, J. Just, M. Klaus, R. Agrawal, T. Unold, Real-time observation of $\mathrm{Cu}_{2} \mathrm{ZnSn}(\mathrm{S}, \mathrm{Se})_{4}$ solar cell absorber layer formation from nanoparticle precursors, Physical Chemistry Chemical Physics 15 (41) (2013) 18281. doi:10.1039/c3cp53373e.

[33] G. Larramona, S. Bourdais, A. Jacob, C. Choné, T. Muto, Y. Cuccaro, B. Delatouche, C. Moisan, D. Péré, G. Dennler, Efficient $\mathrm{Cu}_{2} \mathrm{ZnSnS}_{4}$ solar cells spray coated from a hydro-alcoholic colloid synthesized by instantaneous reaction, RSC Advances 4 (28) (2014) 14655 doi:10.1039/c4ra01707b.

[34] C. Yan, K. Sun, F. Liu, J. Huang, F. Zhou, X. Hao, Boost Voc of pure sulfide kesterite solar cell via a double CZTS layer stacks, Solar Energy Materials and Solar Cells 160 (August) (2017) 7-11. doi:10.1016/j.solmat.2016.09.027.

[35] F. Liu, C. Yan, J. Huang, K. Sun, F. Zhou, J. A. Stride, M. A. Green, $X$. Hao, Nanoscale Microstructure and Chemistry of $\mathrm{Cu}_{2} \mathrm{ZnSnS}_{4} / \mathrm{CdS}$ Interface in Kesterite $\mathrm{Cu}_{2} \mathrm{ZnSnS}_{4}$ Solar Cells, Advanced Energy Materials 6 (15) (2016) 1600706. doi:10.1002/aenm.201600706.

[36] N. Paudel, K. Wieland, A. Compaan, Ultrathin CdS/CdTe solar cells by sputtering, Solar Energy Materials and Solar Cells 105 (2012) 109-112. doi:10.1016/j.solmat.2012.05.035.

[37] Z. J. Li-Kao, N. Naghavi, F. Erfurth, J. F. Guillemoles, I. Gérard, A. Etcheberry, J. L. Pelouard, S. Collin, G. Voorwinden, D. Lincot, Towards ultrathin copper indium gallium diselenide solar cells: proof of concept study by chemical etching and gold back contact engineering, Progress in Photovoltaics: Research and Applications 20 (5) (2012) 582587. doi:10.1002/pip.2162.

[38] O. Lundberg, M. Bodegård, J. Malmström, L. Stolt, Influence of the $\mathrm{Cu}(\mathrm{In}, \mathrm{Ga}) \mathrm{Se}_{2}$ thickness and $\mathrm{Ga}$ grading on solar cell performance, Progress in Photovoltaics: Research and Applications 11 (2) (2003) 7788. doi:10.1002/pip.462

[39] J. K. Larsen, S.-Y. Li, J. J. S. Scragg, Y. Ren, C. Hägglund, M. D. Heinemann, S. Kretzschmar, T. Unold, C. Platzer-Björkman, Interference effects in photoluminescence spectra of $\mathrm{Cu}_{2} \mathrm{ZnSnS}_{4}$ and $\mathrm{Cu}(\mathrm{In}, \mathrm{Ga}) \mathrm{Se}_{2}$ thin films, Journal of Applied Physics 118 (3) (2015) 035307. doi:10.1063/1.4926857.

[40] S.-Y. Li, C. Hägglund, Y. Ren, J. J. Scragg, J. K. Larsen, C. Frisk, K. Rudisch, S. Englund, C. Platzer-Björkman, Optical properties of reactively sputtered $\mathrm{Cu}_{2} \mathrm{ZnSnS}_{4}$ solar absorbers determined by spectroscopic ellipsometry and spectrophotometry, Solar Energy Materials and Solar Cells 149 (2016) 170-178. doi:10.1016/j.solmat.2016.01.014.

[41] A. Crovetto, R. Chen, R. B. Ettlinger, A. C. Cazzaniga, J. Schou, C. Persson, O. Hansen, Dielectric function and double absorption onset of monoclinic $\mathrm{Cu}_{2} \mathrm{SnS}_{3}$ : Origin of experimental features explained by first-principles calculations, Solar Energy Materials and Solar Cells 154 (2016) 121-129. doi:10.1016/j.solmat.2016.04.028.

[42] B. Ohnesorge, R. Weigand, G. Bacher, A. Forchel, W. Riedl, F. H. Karg, Minority-carrier lifetime and efficiency of $\mathrm{Cu}(\mathrm{In}, \mathrm{Ga}) \mathrm{Se}_{2}$ solar cells, Applied Physics Letters 73 (9) (1998) 1224-1226. doi:10.1063/1.122134.

[43] D. K. Schroder, Semiconductor material and device characterization, John Wiley \& Sons, Hoboken, New Jersey, 2006.

[44] S. S. Hegedus, W. N. Shafarman, Thin-film solar cells: device measurements and analysis, Progress in Photovoltaics: Research and Applications 12 (23) (2004) 155-176. doi:10.1002/pip.518.

[45] B. Misic, B. E. Pieters, J. P. Theisen, A. Gerber, U. Rau, Shunt mitigation in $\mathrm{ZnO}: \mathrm{Al} / \mathrm{i}-\mathrm{ZnO} / \mathrm{CdS} / \mathrm{Cu}(\mathrm{In}, \mathrm{Ga}) \mathrm{Se}_{2}$ solar modules by the $\mathrm{i}-\mathrm{ZnO} / \mathrm{CdS}$ buffer combination, physica status solidi (a) 212 (3) (2015) 541-546. doi:10.1002/pssa.201431496.

[46] W. N. Shafarman, S. Siebentritt, L. Stolt, $\mathrm{Cu}(\mathrm{InGa}) \mathrm{Se}_{2}$ Solar Cells, in: A. Luque, S. Hegedus (Eds.), Handbook of Photovoltaic Science and Engineering, John Wiley \& Sons, Ltd, Chichester, UK, 2010, Ch. 13. doi:10.1002/9780470974704.

[47] B. Shin, T. Gershon, S. Guha, CZTS-Based Thin-Film Solar Cells Prepared via Coevaporation, in: K. Ito (Ed.), Copper Zinc Tin Sulfide-Based Thin-Film Solar Cells, Wiley, 2015, Ch. 15, pp. 344-345.

[48] Z. Bai, J. Yang, D. Wang, Thin film CdTe solar cells with an absorber layer thickness in micro- and sub-micrometer scale, Applied Physics Letters 99 (14) (2011) 143502. doi:10.1063/1.3644160. 